\title{
Forest Fire Area Detection by Using Landsat-8 and Sentinel-2 Satellite Images: A Case Study in Mugla, Turkey
}

\section{Bahadir Kurnaz}

Bayburt Universitesi

Caglar Bayik ( $\sim$ caglarbayik@beun.edu.tr)

Zonguldak Bulent Ecevit Universitesi https://orcid.org/0000-0001-6606-3272

\section{Saygin Abdikan}

Zonguldak Bulent Ecevit Universitesi

\section{Research}

Keywords: Remote Sensing, Landsat-8, Sentinel-2, Object Based Classification, Burn Severity

Posted Date: May 11th, 2020

DOI: https://doi.org/10.21203/rs.3.rs-26787/v1

License: (c) (i) This work is licensed under a Creative Commons Attribution 4.0 International License.

Read Full License 
Forest Fire Area Detection by Using Landsat-8 and Sentinel-2 Satellite Images: A Case Study in Mugla, Turkey

\section{Bahadir Kurnaz $^{1}$, Caglar Bayik ${ }^{2 *}$, Saygin Abdikan²}

${ }^{1}$ Aydıntepe Vocational School, Bayburt University, Aydintepe, Bayburt, Turkey (bahadirkurnaz@bayburt.edu.tr)

${ }^{2}$ Department of Geomatic Engineering, Zonguldak Bulent Ecevit University, 67100 Zonguldak, Turkey (sabdikan@beun.edu.tr, caglarbayik@beun.edu.tr)

*Corresponding Author 


\begin{abstract}
Background: Forests have an extremely important place in the ecosystem in terms of ensuring social and environmental balance. The biggest danger for forests that have this importance is forest fires due to various reasons. It is extremely important to estimate the formation and behavior characteristics of fires in terms of combating forest fires. Using the satellite images obtained with the developing technology for this purpose provides great convenience in the detection of the fire areas and the severity of the fire affected. In this study, forest fire that occurred in the Zeytinköy region of Muğla province was investigated using remotely sensed images. According to the reference data provided by the General Directorate of Forestry (GDF), 425 hectares of area was destroyed by fire. In this study, it is aimed to extract burn scar by applying seven vegetation indexes on Sentinel- 2 and Landsat- 8 satellite images. Additionally, forest fire areas have been determined with the object-based classification technique.
\end{abstract}

Results: As a result of the study, when the obtained results are compared with the values obtained from GDF, it is determined that object based analysis of Sentinel-2 provided the highest accuracy with $98.36 \%$ overall accuracy and 0.976 kappa statistics. Comparing the results of spectral indices of Sentinel-2 and Landsat-8, Sentinel-2 resulted better results in all indices. Among the indices RdNBR and dNDVI obtained better results than other indices with Sentinel-2 and Landsat-8, respectively.

Conclusions: In general, it has been determined that Sentinel-2 data is more suitable than Landsat-8 satellite images for determining Turkish red pine forest fired areas. Red and near infrared based images can be used for rapid mapping of fired areas. The results also indicated that the indices provided by multi-temporal Sentinel-2 data can assist forest management for rapid monitoring of fire scars and also for evolution of reforestation after fire.

Keywords: Remote Sensing; Landsat-8; Sentinel-2; Object Based Classification; Burn Severity

\title{
1. Background
}

Forest fires caused by human or natural causes can leave long-term and destructive effects on the ecosystem. Due to its climate Mediterranean is one of mostly effected region by fires (Quintano et al. 2018). Located in the Mediterranean region, Turkey where mostly semi-arid, dry sub-humid and semi-humid climate is dominant, forest fires are a serious threat and poses a great risk (Türkeş et al. 2012). $60 \%$ of the total forest assets constitute the regions that constitute first and second degree fire threats. Besides, $29 \%$ of Turkey's surface area consists of forest assets. This corresponds to an area of 22.7 million hectares. Approximately 13.1 million hectares of this area constitute a closed forest area and 9.6 million hectares make up a hollow closed forest area (GDF Report 2020). The destruction of forests, which are of great importance for our lives, due to fires causes damages such as landslides, erosion and desertification. In order to eliminate these problems, determining the severity of the fire and rehabilitating the destroyed areas is of great importance. In order for the fight against forest fires to be successful, it may not enough to take the necessary measures on time. In addition, 
advanced technology should be used very effectively at every stage of firefighting (Aricak et al. 2012). Remote sensing methods have been used for a long time to detect damage caused by forest fires (Yurtseven 2014). The possibilities offered by remote sensing methods are used in areas such as mapping fire areas, determining the severity of burning, fire management and detection of burnt areas in space.

Image classification and fire index methods are frequently used in determining the temporal change in forest areas and burning severity analysis. Özkan (1998), examined the fire that started in July 1996 in Marmaris district of Muğla and lasted for four days through Landsat TM, SPOT P and IRS-1C satellite images. In the study, vegetation index (VI), normalized difference vegetation index (NDVI) and transformed normalized difference vegetation index (TNDVI) were applied to the image. The results were compared with the maps of the regional directorate of the forest and accuracy analysis was done. Xiao et al. (2003) applied the NDVI and EVI fire indexes to the pre-fire and post-fire images of the SPOT-4 satellite of the region in order to examine the change in plant indexes in a fire in North Asia. By taking the difference of these image indices, they examined the differences in carbon emission, biomass loss and ash formation. As a result, they determined the fire threshold values and used these threshold values to determine the fire intensity. Escuin et al. (2008), applied Normalized Burn Ratio (NBR) and NDVI indexes on Landsat satellite images to analyze three different fires that occurred in Cazorla, Nerva and Anzalcollar regions of Southern Spain in 1995 and 2001. NIR and MIR bands are preferred because they are the most suitable bands to reveal the fire characteristics. Vlassova et al. (2014), analyzed time series of NDVI extracted from Landsat TM to determine the effect of fire occurred in Caceres province of Spain and post vegetation after the region. Tombul (2015), studied Landsat-7 and MODIS satellite images to monitor forest fires occurred in the Mediterranean region using NBR and difference NBR (dNBR) indices. In the following period, NDVI index images of the burned areas were obtained and the renewal and improvement studies were examined.

Mallinis et al. (2018) compared indices derived from Landsat-8 and Sentinel-2 and investigated their relation with field based indices. Among the indices dNBR of Sentinel-2 indicated the highest correlation with in-situ based analysis while comparing Landsat-8. Quintano et al (2018) investigated the burn severity using Landsat- 8 and Sentinel-2 using three indices dNBR, Relative dBNR (RdNBR) and Relativized Burn Ratio (RBR). Pléiades image used as reference and the results showed that Landsat based RdNBR reached highest accuracy. Garcia-Llamas et al. (2019) examined a forest fire that occurred in Cabrere mountainous region in northwestern Spain in August 2017 using Landsat-8, Sentinel-2 and Deimos-1 satellite data. They applied reflective, thermal and mixed indices on the images and concluded that Sentinel-2 indicated slightly better results and NBR based indices provided higher correlation for site, vegetation and soil burn severity analysis.

Object based image classification method has been also used in different studies to determine damaged regions due to forest fire. Mitri and Gitas (2006) used high resolution Ikonos data to detect fire effected areas and concluded that density of the canopy mainly affected the accuracy which is overall $87 \%$ and 0.74 kappa coefficient. Polychronaki and Gitas (2012) showed high accuracies which is approximately 0.86 kappa coefficient using SPOT images. Dragozi et al. 
(2015) also used high resolution images for the burn severity estimation. They used GeoEye images and determined approximate accuracy of $\% 72$ and $\% 82$ for the two dataset. A recent study identified fire severity applying ten indices on Landsat data and concluded that dGEMI provided the most robust approach for heterogeneous tundra covered region (Chen et al. 2020). In this study, we evaluate the performance of Landsat- 8 and Sentinel-2 for the determination of burned area in a homogeneous coniferous dominated forest and agriculture covered region. It is aimed to identify suitable satellite and indice for the delineation of the burned area and severity mapping. Kurnaz et al. (2019) indicated the first results of object based image analysis (OBIA) of the study area and in this study we extend that study and applied seven indices namely dNBR, RBR, RdNBR, dNDVI, dGNDVI, BAI and GEMI to identify the burned area which is approximately 425 hectares and burn severity analysis. The resulting products have been compared with the in situ data provided by the Denizova Forest Enterprise Directorate, and accuracy analyzes were performed.

\section{Study Area and Dataset}

\subsection{Study Area}

As the study area, Muğla Province, Menteşe District, Zeytinköy District, where there are dense pine forests (Pinus brutia or Turkish red pine), was chosen (Figure 1). The city, which is neighbor with Aydın in the north, Denizli and Burdur in the northeast, Antalya in the east, is surrounded by the Mediterranean Sea in the south and the Aegean Sea in the west. Due to the abundant precipitation and appropriate temperature, there is a great variety in terms of forest cover. Although the dominant vegetation is scrub in the region, $65 \%$ of the district is covered with forests. In the study area, a fire occurred at noon on September 6, 2017, and it was only under control at noon on September 7, 2017. As a result of the fire, most of the Zeytinköy neighborhood and the forests surrounding the village were destroyed.
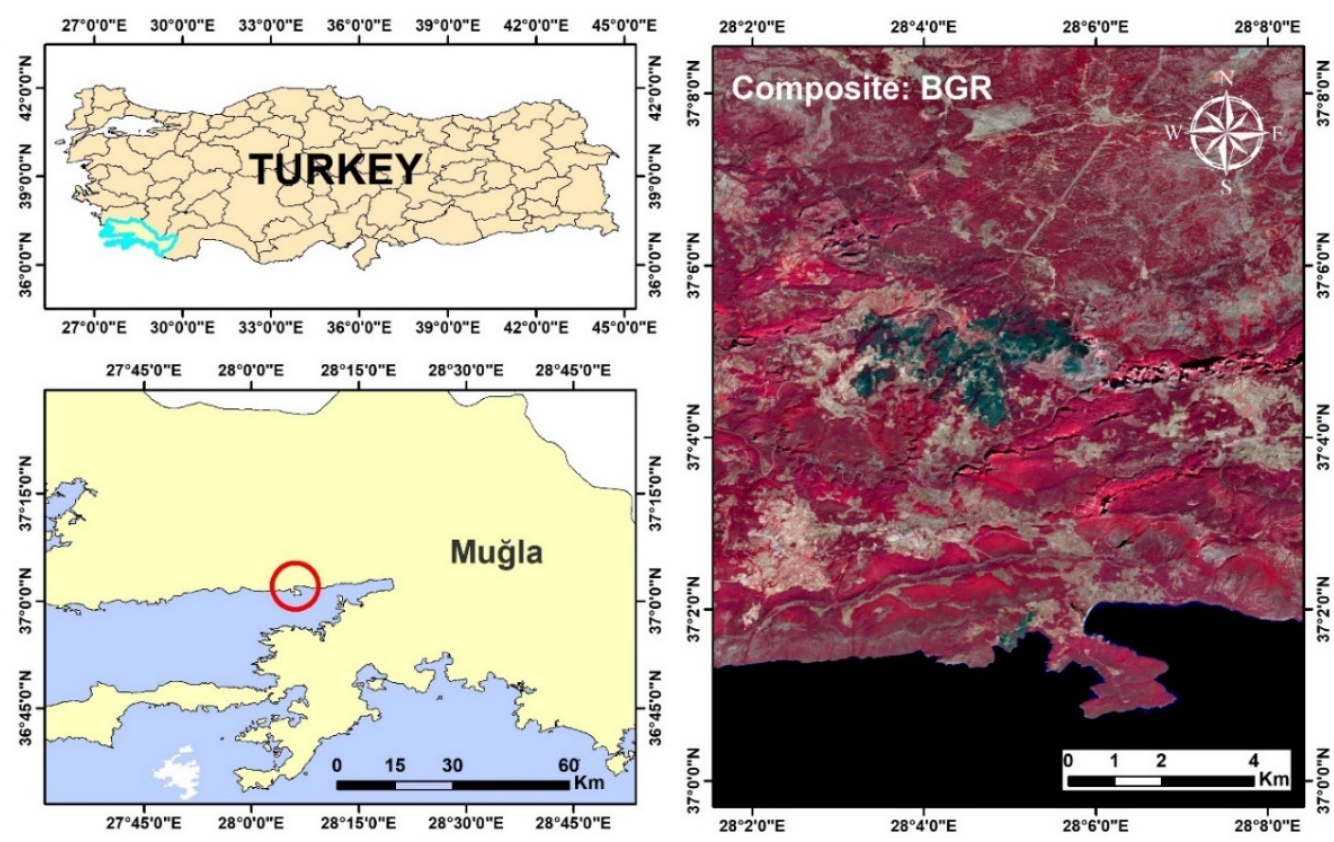

Fig. 1 Study area 


\subsection{Dataset}

\subsubsection{Satellite data}

One of the satellite images used in this study is the medium resolution satellite data of Landsat8 satellite. The images were obtained by USGS (United States Geological Survey) website. Landsat- 8 is the eighth satellite in the series and it is ensured that the most important role of the Landsat program continues in determining and monitoring the necessary resources for human livelihoods such as food, water and forests Landsat-8 satellite has 2 new sensors: OLI (operational land imager) and TIRS (thermal infrared sensor).

In addition to the Landsat- 8 satellite image, Sentinel- 2 satellite data was also used in this study to identify and compare the burned areas. The images used were obtained by SCIHUB (Sentinels Scientific Data Hub) of European Space Agency (ESA) free of charge. The Sentinel2 series consists of two satellites, Sentinel 2A and 2B. Sentinel-2A was launched in June 2015 and Sentinel-2B in July 2016. The two satellites are in the same orbit and $180^{\circ}$ to each other. Sentinel-2 satellites offer a unique perspective for viewing vegetation and the earth with its wide lane width, high spatial resolution and 13 spectral bands. The Sentinel-2 satellite is a satellite with a multispectral high-resolution sensor and aimed to perform field analysis such as vegetation, soil and water coverage areas. It also provides access to information within emergency services. Spectral and spatial information for Landsat-8 and Sentinel-2 satellites are given in Table 1 .

Table 1. Properties of Landsat-8 and Sentinel-2 satellites

\begin{tabular}{cccccccccc}
\hline $\begin{array}{c}\text { L8 } \\
\text { Band }\end{array}$ & & $\begin{array}{c}\text { Wavelength } \\
\text { (min-max) }\end{array}$ & $\begin{array}{c}\text { Band } \\
\text { width }\end{array}$ & $\begin{array}{c}\text { Res. } \\
(\mathbf{m})\end{array}$ & $\begin{array}{c}\text { S2 } \\
\text { Band }\end{array}$ & & $\begin{array}{c}\text { Wavelength } \\
\text { (min-max) }\end{array}$ & $\begin{array}{c}\text { Band } \\
\text { width }\end{array}$ & $\begin{array}{c}\text { Res. } \\
(\mathbf{m})\end{array}$ \\
\hline 1 & C/A & $0.435-0.451$ & 0.016 & 30 & 1 & C/A & $0.421-0.457$ & 0.036 & 60 \\
2 & Blue & $0.452-0.512$ & 0.060 & 30 & 2 & Blue & $0.439-0.535$ & 0.096 & 10 \\
3 & Green & $0.533-0.590$ & 0.057 & 30 & 3 & Green & $0.537-0.582$ & 0.045 & 10 \\
4 & Red & $0.636-0.673$ & 0.037 & 30 & 4 & Red & $0.646-0.685$ & 0.039 & 10 \\
& & & & & 5 & VRE & $0.694-0.714$ & 0.020 & 20 \\
& & & & & 6 & VRE & $0.731-0.749$ & 0. & 20 \\
& & & & & & & & 018 & \\
& & & & & 7 & VRE & $0.768-0.796$ & 0.028 & 20 \\
5 & NIR & $0851-0.879$ & 0.028 & 30 & 8 & NIR & $0.767-0.908$ & 0.141 & 10 \\
& & & & & $8 \mathrm{a}$ & NIRn2 & $0.848-0.881$ & 0.033 & 20 \\
& & & & & 9 & WV & $0.931-0.958$ & 0.027 & 60 \\
9 & Cirrus & $1.363-1.384$ & 0.020 & 30 & 10 & Cirrus & $1.338-1.414$ & 0.076 & 60 \\
6 & SWIR & $1.567-1.651$ & 0.085 & 30 & 11 & SWIR & $1.539-1.681$ & 0.142 & 20 \\
7 & SWIR2 & $2.107-2.294$ & 0.187 & 30 & 12 & SWIR2 & $2.072-2.312$ & 0.240 & 20 \\
8 & Pan & $0.503-0.676$ & 0.172 & 15 & & & & & \\
10 & TIRS & $10.60-11.19$ & 0.590 & 100 & & & & & \\
11 & TIRS & $11.50-12.51$ & 1.010 & 100 & & & & & \\
\hline
\end{tabular}


For the determination of the area after the fire, satellite images of Landsat- 8 satellite before the fire on August 26, 2017, after the fire on September 11, 2017, and on the satellite images of the Sentinel-2 before the fire on August 31, 2017, after the fire on September 7, 2017 were acquired. Since the study area was chosen as a forest area, the infrared band, in which the green areas had the best reflection value, was changed by changing the band order and continued to work with a new pseudo color image. Figure 2 shows the post-fire status of the Landsat- 8 satellite image of the study area, while Figure 3 shows the post-fire status of the Sentinel-2 satellite image.

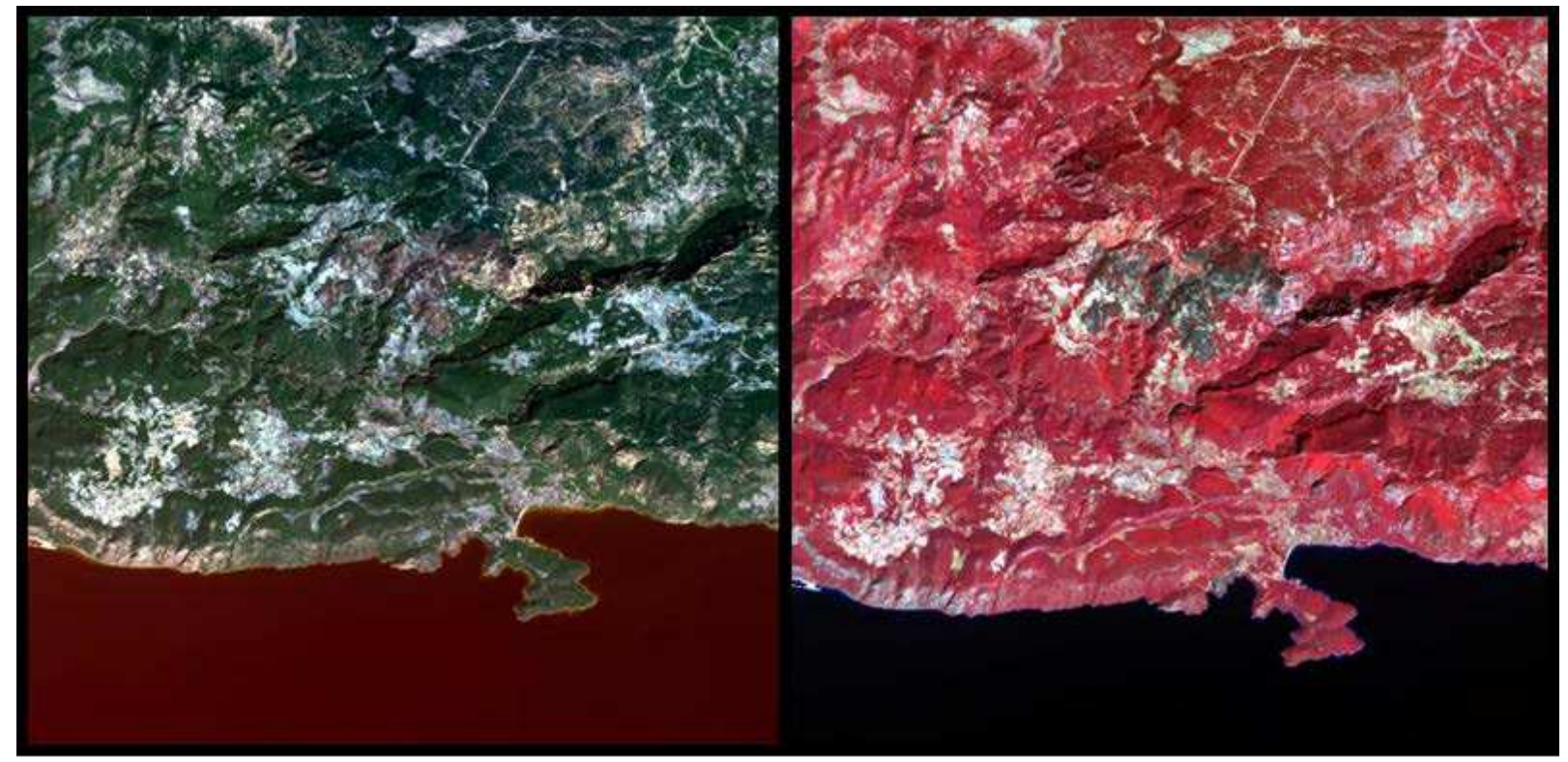

Fig. 2 Landsat-8 satellite of the study area after the fire a) true color (B4, B3, B2), b) false color (B5, B3, B2)

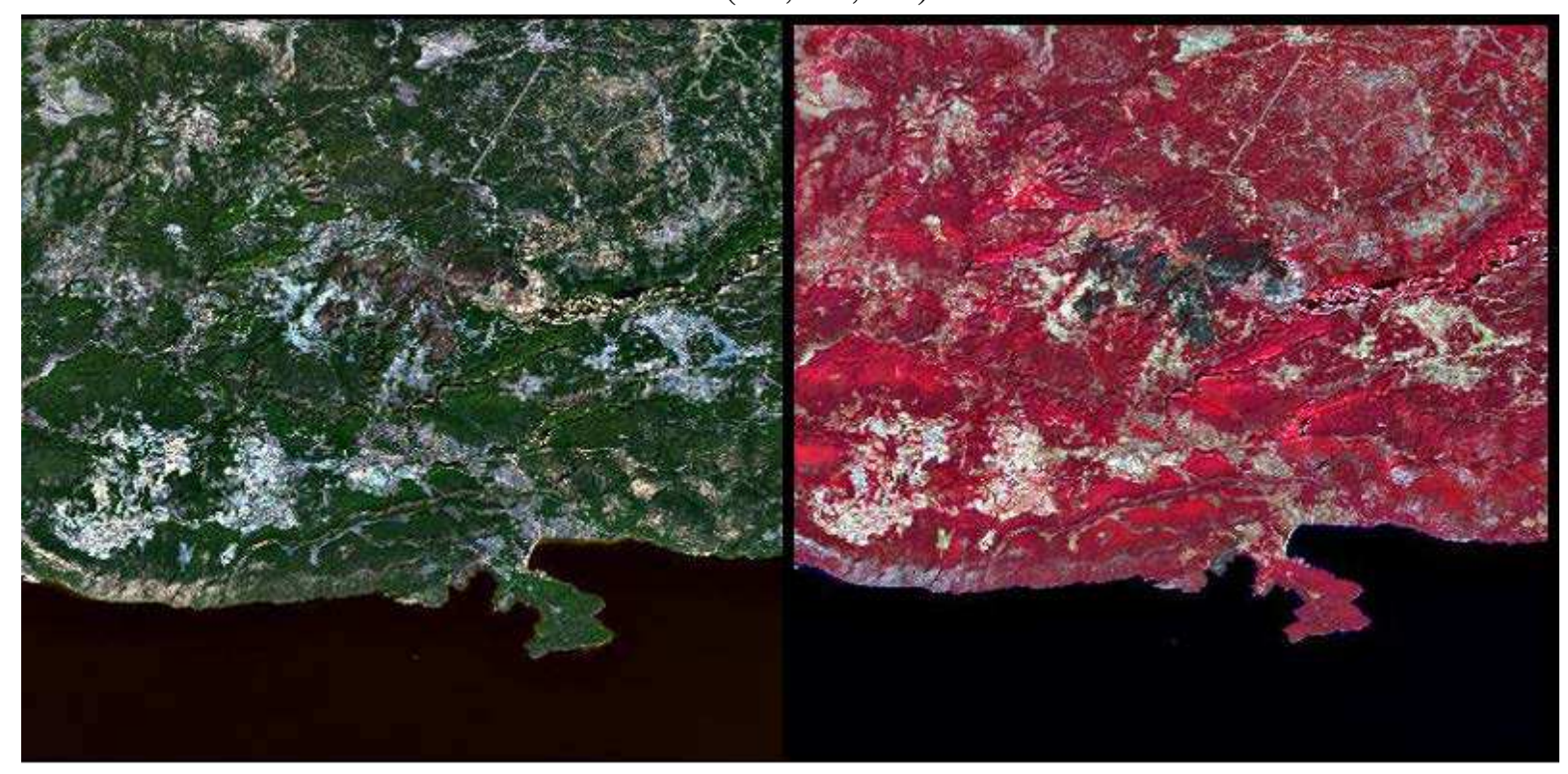

Fig 3. Sentinel-2 satellite of the study area after the fire a) true color (B4, B3, B2), b) false color (B8, B3, B2) 


\subsubsection{In situ Data}

The Zeytinköy fire of Muğla province, Menteşe district, which was handled within the scope of this study, broke out on 06.09.2017, was taken under control on 07.09.2017 and was completely extinguished on 25.09.2017. According to the data of General Directorate of Forestry (GDF), 425 hectares of forest and agricultural land were affected by this fire. Maximum temperature and humidity was recorded as $32 \mathrm{C}^{\circ}$ and $25 \%$ respectively. Fire start and extinguishing dates, fire coordinates, amount of burning area, type of mosque affected by fire, number of teams interfering with the fire, etc. containing the information was obtained from the Denizova Forest Management Directorate affiliated with the Muğla Forest Management Directorate.

\section{Methodology}

In this study, a forest fire that occurred in the Zeytinköy District of Menteşe District of Muğla Province, where frequent pine forests and agricultural lands are located, is discussed. The forest fire started on 06.09.2017 at 13:40 and was taken under control on 07.09.2017 at 11:00. During this period, 225 ha forest area and 200 ha agricultural area have been destroyed. With the Landsat-8 and Sentinel-2 satellite image indexes, object-based classification techniques, burning area and burning intensity were determined and the differences in the detection of burning area were compared.

\subsection{Subsection}

\subsubsection{Spectral Indexes}

In this study, seven vegetation indices namely dNBR, RBR, RdNBR, dNDVI, dGNDI, GEMI and BAI are created using arithmetic calculations of bands. Normalized Difference Vegetation Index (NDVI) is produced using the near infrared band that the vegetation strongly reflects and the red band where the vegetation shows absorption (Tucker 1979). It is calculated by division of the difference of NIR and red bands to sum of the same bands. Higher values indicates dense vegetation cover.

While applying Differenced Normalized Difference Vegetation Index (dNDVI), NDVI indexes are created by making use of the near infrared and red bands of the image on both pre and post event dates as the first step. Then, the dNDVI index is obtained by subtracting the NDVI index after the fire from the NDVI index before the fire. Normalized Burn Ratio (NBR) index is one of the most actively used indexes in fire observation studies conducted with remote sensing studies. NBR index, near infrared (NIR) and short wave infrared bands (SWIR) values are applied by proportioning their differences and totals (Roy et al. 2006). The NBR index is expressed in values between -1 and +1 . Since the reduction in vegetation will occur in the process after the fire, near infrared band reflection is greatly reduced. Healthy vegetation generally gives high values, while empty terrain or recently burned areas give low index values. 
Differenced Normalized Burn Ratio (dNBR), determines the scar of burned regions using difference of NBR calculated from pre and post event images (Mallinis et al. 2017). Since the gray values in the NBR index before fire are larger than the gray values in the burned areas after the fire, it can be understood that the fire has occurred in areas with positive gray values in the dNBR index, while the areas with negative values are not affected by the fire.

Relative differenced Normalized Burn Ratio (RdNBR) uses NBR calculated from pre-fire satellite images, as well as dNBR from pre- and post-fire images, to measure spectral variation (Miller and Thode 2007). Another NBR based alternative index is called Relativized Burn Ratio $(R B R)$ that is the ratio of dNBR to NBR calculated from pre-fire image (Parks et al. 2014).

Green Normalized Difference Vegetation Index (GNDVI) replaces red band to green band. It has been stated to be particularly useful for distinguishing stressful vegetation (Gitelson and Merzlyak 1998). Differenced Green Normalized Difference Vegetation Index (dGNDVI) identify the burned area using difference of GNDVI calculated from pre and post event images.

Global Environmental Monitoring Index (GEMI) was proposed to discriminate vegetation to other surfaces using atmospherically reduced visible and NIR bands (Pinty and Verstraete 1992).

Burn Area Index (BAI) was designed by Chuvieco et al. (2002) using red and NIR spectral domain. The index stresses the charcoal signal that can be seen in post-event images. Chuvieco et al. (2002) indicated that the index has more ability to delineate burned areas than NDVI, GEMI and SAVI while using Landsat.

\subsection{Object-based Classification}

Using the Sentinel-2 and Landsat-8 satellite images, post-fire changes are identified with object-based classification analysis for specified classes. In this case five classes as bareland, coniferous, deciduous, water and burned area was selected. For the object-based classification method, eCognition software was used. Multi resolution segmentation method is applied as a first step. The output of the segmentation depends of the scale, shape and compactness parameters driven by the user (Novalli et al. 2016). The scale parameter that controls the size of the segment determines the maximum heterogeneity. The value of the selected scale parameter directly affects the partitioning of the image by determining the size of the objects in the image. While shape parameter rules the weight of color, compactness defines how close the pixels for an object comparing to a circle (Delen et al. 2019). For the supervised image classification fuzzy rule based integrated nearest neighbor classification method is used. The user accuracy (UA), producer accuracy (PA) and kappa values were determined for the accuracy analysis of the classified images (Kurnaz 2019). 


\section{Results}

\subsection{Vegetation indices}

The vegetation indices were applied for the images acquired from Landsat- 8 and Sentinel-2. The related band combinations were illustrated in Table 2 . The scar of fire burn is clearly visible in both post-event data. In each indice the change regarding to fire and no-change classes were identified using threshold values and the images were converted to binary image. The results indicated that dNDVI and RdNBR provided better results among the other indices comparing the fired amount determined by GDF. These two indices can be seen in Fig. 4 which discriminate fire scar using Sentinel-2 and Landsat-8. In all images the fired regions appears bright than the rest of the image. For the severity analysis, according to threshold values four classes were determined applying on the high results provided in both cases by dNDVI index (Fig. 5). When we look at the fire intensity maps, it can be seen that there is a fire with high burning intensity in Sentinel-2 that is extracted as moderate-high in Landsat-8 result.

Table 2. Vegetatation indices using Sentinel-2 and Landsat-8 satellite images

\begin{tabular}{|c|c|c|}
\hline Indices & Sentinel-2 & Landsat-8 \\
\hline \multirow{2}{*}{ NBR } & B8-B12 & B5 - B7 \\
\hline & $\overline{\mathrm{B} 8+\mathrm{B} 12}$ & $\overline{\mathrm{B} 5+\mathrm{B} 7}$ \\
\hline \multirow{2}{*}{ NDVI } & $\mathrm{B} 8-\mathrm{B} 4$ & B5 - B4 \\
\hline & $\overline{\mathrm{B} 8+\mathrm{B} 4}$ & $\overline{\mathrm{B} 5+\mathrm{B} 4}$ \\
\hline dNDVI & $\mathrm{NDVI}_{\text {pre-fire-NDVI }}$ post-fire & $\mathrm{NDVI}_{\text {pre-fire-NDVI }}$ post-fire \\
\hline \multirow{2}{*}{ GNDVI } & $\mathrm{B} 8-\mathrm{B} 3$ & B5 - B3 \\
\hline & $\overline{\mathrm{B} 8+\mathrm{B} 3}$ & $\overline{\mathrm{B} 5+\mathrm{B} 3}$ \\
\hline dGNDVI & GNDVI $_{\text {pre-fire-GNDVI }}$ post-fire & GNDVI $_{\text {pre-fire-GNDVI }}$ post-fire \\
\hline dNBR & NBR pre-fire- NBR post-fire & NBR pre-fire- NBR post-fire \\
\hline \multirow{2}{*}{ RdNBR } & dNBR & dNBR \\
\hline & $\sqrt{\left|\mathrm{NBR}_{\text {pre-fire }} / 1000\right|}$ & $\sqrt{\left|\mathrm{NBR}_{\text {pre-fire }} / 1000\right|}$ \\
\hline \multirow{2}{*}{ RBR } & dNBR & dNBR \\
\hline & $\overline{\text { NBR }_{\text {pre-fire }}+1.001}$ & $\overline{\text { NBR }_{\text {pre-fire }}+1.001}$ \\
\hline \multirow{2}{*}{ BAI } & 1 & 1 \\
\hline & $\overline{(0.1-B 4)^{2}+(0.06-B 8)^{2}}$ & $\overline{(0.1-B 4)^{2}+(0.06-B 5)^{2}}$ \\
\hline \multirow[t]{3}{*}{ GEMI } & $\gamma *(1-0.25 * \gamma)-\frac{B 4-0.125}{1-B 4}$ & $\gamma *(1-0.25 * \gamma)-\frac{B 4-0.125}{1-B 4}$ \\
\hline & $2 *\left(B 8^{2}-B 4^{2}\right)+1.5 * B 8+0.5 * B 4$ & $2 *\left(B 5^{2}-B 4^{2}\right)+1.5 * B 5+0.5 * B 4$ \\
\hline & $B 8+B 4+0.5$ & $B 5+B 4+0.5$ \\
\hline
\end{tabular}




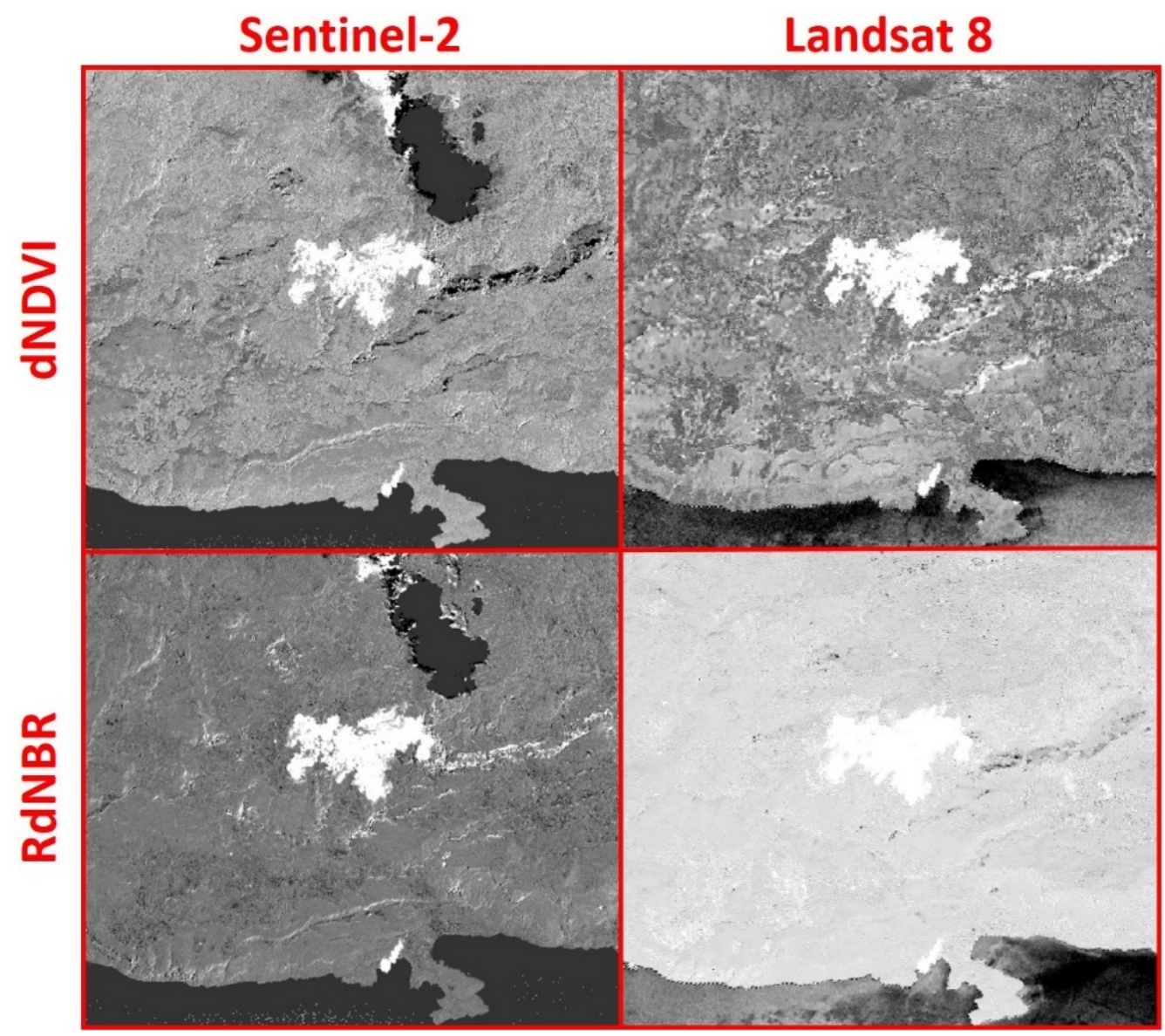

Fig. 4 dNDVI and RdNBR results of Sentinel-2 and Landsat-8
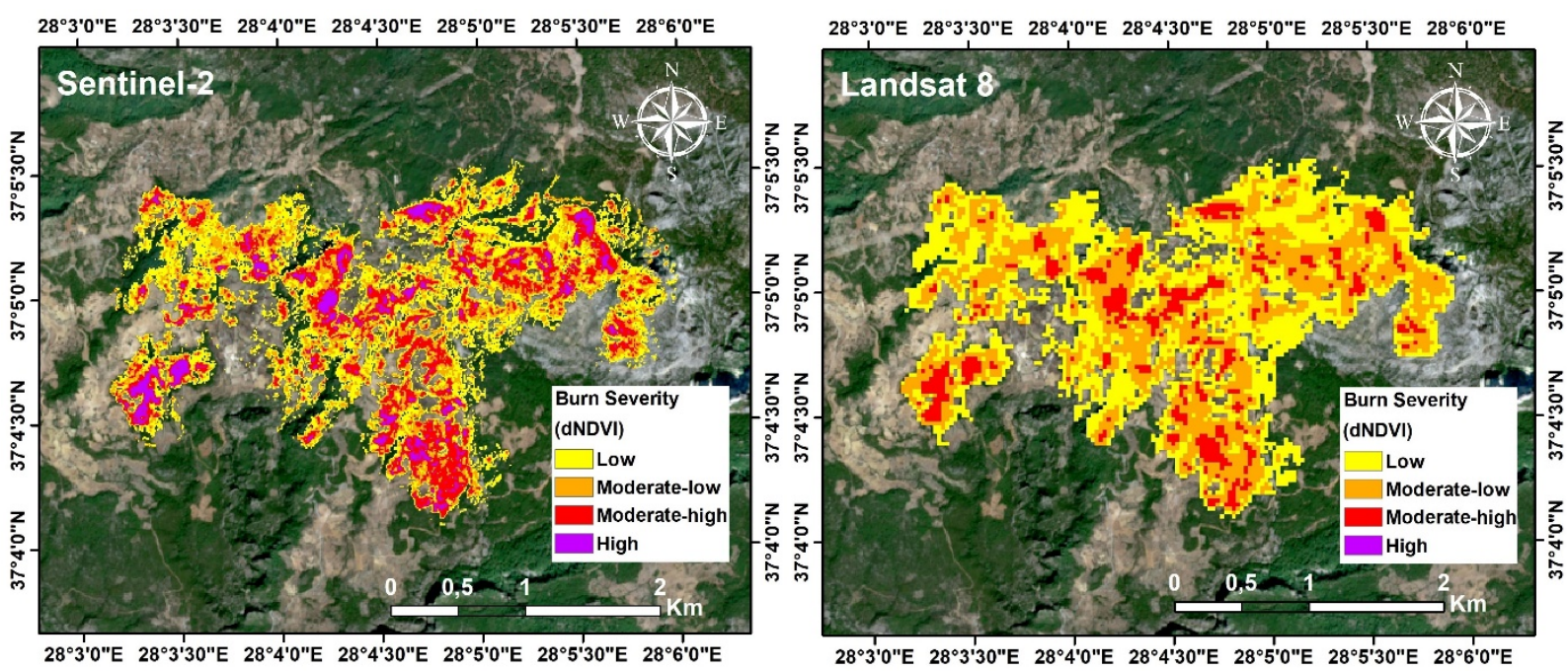

Fig. 5 Severity analysis using dNDVI of Sentinel-2 and Landsat- 8

\subsection{Object-based Classification}

In the object based classification post-event of Sentinel- 2 and Landsat- 8 images were used. The segmentation step was completed with the chosen parameters 100 for scale, 0.5 for compactness and 0.1 for shape in both images. After the segmentation six classes as burned area, bareland, coniferous, deciduous, and water classes were determined. The accuracy of the classified image 
was assessed with user accuracy, producer accuracy and kappa statistics. The results of OBIA concluded that Sentinel-2 image has $98.36 \%$ overall accuracy and 0.976 kappa and Landsat-8 provided $96.31 \%$ overall accuracy and 0.951 kappa value (Table 3 ).

Table 3. Accuracy assessment of OBIA.

\begin{tabular}{|c|c|c|c|c|c|c|}
\hline \multirow[b]{2}{*}{ Classes } & \multicolumn{3}{|c|}{ Landsat-8 (\%) } & \multicolumn{3}{|c|}{ Sentinel-2 (\%) } \\
\hline & PA (\%) & UA (\%) & Kappa & PA (\%) & UA $(\%)$ & Kappa \\
\hline Coniferous & $100.00 \%$ & $95.80 \%$ & 1.000 & $99.39 \%$ & $97.60 \%$ & 0.993 \\
\hline Deciduous & $95.65 \%$ & $93.62 \%$ & 0.947 & $99.55 \%$ & $99.55 \%$ & 0.994 \\
\hline Water & $91.67 \%$ & $100.00 \%$ & 0.909 & $95.38 \%$ & $100.00 \%$ & 0.951 \\
\hline Bareland & $96.23 \%$ & $97.28 \%$ & 0.941 & $99.62 \%$ & $97.79 \%$ & 0.992 \\
\hline Burned area & $92.31 \%$ & $97.96 \%$ & 0.915 & $90.43 \%$ & $99.04 \%$ & 0.894 \\
\hline $\begin{array}{l}\text { Overall } \\
\text { Accuracy }\end{array}$ & $96.31 \%$ & & & $98.36 \%$ & & \\
\hline Kappa & 0.951 & & & 0.976 & & \\
\hline
\end{tabular}

\section{Discussion and Conclusion}

This section is mandatory but can be added to the manuscript if the discussion is unusually long or complex. In this study, the importance of remote sensing science in mapping, analysis and detection of forest fires is emphasized. In this way, instead of the costly and time-consuming works carried out on the land, it was examined with the developing technology and the results of certain precision and accuracy in a much more economical, fast and risk-free way. It is aimed to contribute to future studies by using different satellite methods, algorithms, bands and indexes in the study. The aim of the study is to investigate fire indexes and object-based classification results using satellite images in line with the determination of fire areas and burning severity in forest areas. The advantages and disadvantages of the results obtained after the research have been evaluated and the method that has a suitable result has been determined. The differences between the obtained result indexes, the object-based classification results and the fire areas and GDF are given in Table 4.

Table 4. Forest fire areas obtained from indices and OBIA.

\begin{tabular}{ccccc}
\hline Index (ha) & Sentinel-2 & $\begin{array}{c}\text { Difference } \\
\text { from GDF } \\
\text { data. }\end{array}$ & Landsat-8 & $\begin{array}{c}\text { Difference } \\
\text { from GDF } \\
\text { data. }\end{array}$ \\
\hline dNBR & 484,28 & 59,28 & 579,24 & 154,24 \\
RBR & 481,05 & 56,05 & 583,29 & 158,29 \\
RdNBR & 449,23 & 24,23 & 581,58 & 156,58 \\
dNDVI & 396,60 & 28,4 & 493,11 & 68,11 \\
dGNDVI & 373,45 & 51,55 & 300,06 & 124,94 \\
BAI & 293,24 & 131,76 & 280,08 & 144,92 \\
GEMI & 384,73 & 40,27 & 219,6 & 205,4 \\
Object-based & 431,57 & 6,57 & 513,15 & 88,15 \\
\hline
\end{tabular}


The RdNBR and dNDVI is the most accurate index in Sentinel-2 and Landsat- 8 index, respectively according to the data obtained from GDF. It is also noticed that dNDVI is the second best index in Sentinel-2. The BAI index was the lowest index for Sentinel-2 while GEMI was the lowest for Landsat- 8 images. Considering all the applied indexes and object-based classification analysis, the classified Sentinel-2 image gave the highest accuracy. In the results of Sentinel-2 data RdNBR provided highest value after image classification. The results is similar to Garcia-Llamas et al. (2019) that derived the best results for vegetation burn by $\mathrm{RdNBr}$ index while comparing Sentinel-2 and Landsat-8.

Comparing the object-based classification analysis Sentinel-2 image has higher accuracy than Landsat- 8 image. When the accuracy analysis of the object-based classification method is examined, it is seen that the general accuracy of the classification applied to the Sentinel-2 image is $98.36 \%$ and the general accuracy of the classification applied to the Landsat- 8 image is $96.31 \%$. Similar results also determined by Novalli et al. (2016), and Labib and Harris (2018) while comparing OBIA of Landsat- 8 and Sentinel-2 data.

When the difference indices and object-based classification results applied in terms of burning forest area are analyzed, the analyzes made with Sentinel- 2 images gave higher accuracy results than those made with Landsat- 8 images according to the amount of burning area received from GDF. In the lack of SWIR band GEMI index could be considered alternative to dNDVI index of Sentinel-2.

The reason that the object-based classification gives higher accuracy results on the Sentinel-2 satellite is intended to have a higher spatial resolution than the Landsat- 8 satellite image. Because the pixel dimensions are reduced in high spatial resolution and the image consists of more pixels. Since the same segmentation parameters are selected for both satellite images, the software has divided the high resolution Sentinel-2 satellite image into smaller areas. In the classification process in the Landsat- 8 satellite image with larger pixel dimensions, the burnt areas were overestimated. This is due to the fact that the pixel size is high and therefore, when a whole pixel is not burnt, it classifies that pixel as burnt. Although, object-oriented classification gave better results it requires expertise. Even the threshold values might vary according to the selected index and case, it is an advantageous method for rapid mapping as it quickly determines the burnt area and severity mapping. Overall, both satellites have potential to provide cost-effective conclusions to monitor and manage fires over large areas where dense Mediterranean pine forest is covered.

\section{List of Abbreviations}

GDF: General Directorate of Forestry

NBR: Normalized Burn Ratio

dNBR: differenced Normalized Burn Ratio

RBR: Relativized Burn Ratio

RdNBR: Relative differenced Normalized Burn Ratio

NDVI: Normalized Difference Vegetation Index 
dNDVI: differenced Normalized Difference Vegetation Index

GNDVI: Green Normalized Difference Vegetation Index

dGNDVI: differenced Green Normalized Difference Vegetation Index

BAI: Burn Area Index

SAVI: Soil-adjusted Vegetation Index

GEMI: Global Environmental Monitoring Index

USGS: United States Geological Survey

OLI: Operational Land Imager

TIRS: Thermal Infrared Sensor

SCIHUB: Sentinels Scientific Data Hub

ESA: European Space Agency

NIR: Near Infrared

SWIR: Short Wave Infrared

UA: User Accuracy

OBIA: Object-based Image Analysis

Ethical Approval and Consent to participate

Not applicable

\section{Consent for publication}

Not applicable

\section{Availability of supporting data}

Not applicable

\section{Competing interests}

Not applicable

\section{Funding}

Not applicable

\section{Author Contributions}

C.B. and S.A. conceived and designed the experiments; B.K. and C.B. performed the experiments; B.K. and C.B. analyzed the data; B.K., C.B. and S.A. contributed analysis and visualization; B.K., C.B. and S.A. wrote the paper.

\section{Acknowledgements}

The authors are grateful to the Denizova Forest Management Directorate affiliated with the Muğla Forest Management Directorate for providing fire information and the Research and Service Support team of the European Space Agency (ESA) and the United States Geological Survey (USGS) for providing Sentinel-2 and Landsat-8 imagery. 


\section{References}

Arıcak B, Enez K, Küçük Ö (2012) Uydu Görüntüsü Kullanarak Yangın Potansiyelinin Belirlenmesi, KSU Mühendislik Bilimleri Dergisi, Özel Sayı, 220.

Chen Y, Lara MJ, Hu FS (2020) A robust visible near-infrared index for fire severity mapping in Arctic tundra ecosystems, ISPRS Journal of Photogrammetry and Remote Sensing 159: 101113. https://doi.org/10.1016/j.isprsjprs.2019.11.012.

Chuvieco E, Martin MP, Palacios A (2002) Assessment of different spectral indices in the rednear-infrared spectral domain for burned land discrimination. International Journal of Remote Sensing 23: 5103-5110. https://doi.org/10.1080/01431160210153129.

Delen A, Abdikan S, Balik Sanli F, Bektaş Balçik F, Göksel Ç (2019) Object Based Flooding Extent Mapping With Sentinel-2 Data, 9th International Symposium on Atmospheric Sciences, ATMOS 2019, 23-26 Nov 2019, İstanbul.

Dragozi E, Gitas IZ, Stavrakoudis DG, Minakou C (2015) Burn severity estimation using GeoEye imagery, object-based image analysis (OBIA), and Composite Burn Index (CBI) measurements, Proceedings Volume 9535, Third International Conference on Remote Sensing and Geoinformation of the Environment (RSCy2015); 953515.

Escuin S, Navarro R, Fernández P (2008) Fire Severity Assessment By Using NBR (Normalized Burn Ratio) and NDVI (Normalized Difference Vegetation Index) Derived From Landsat TM/ETM Images. International Journal of Remote Sensing 29(4): 10531073. https://doi.org/10.1080/01431160701281072.

GDF Report for the year

2020: https://www.ogm.gov.tr/ekutuphane/FaaliyetRaporu/Forms/AllItems.aspx Accessed 27.04.2020.

Kurnaz B (2019) Determination of Forest Fire Area by Using Landsat-8 and Sentinel-2 Satellite Images: Muğla Case, M.Sc. Thesis, Zonguldak Bülent Ecevit University, Zonguldak Turkey.

Kurnaz B, Bayik C, Abdikan S (2019) Determination of Forest Fire Area by Using Satellite Images: Muğla Case, 3rd International Conference on Advanced Engineering Technologies 1921 September 2019, Bayburt Turkey.

Labib SM, Harris A (2018) The potentials of Sentinel-2 and LandSat-8 data in green infrastructure extraction, using object based image analysis (OBIA) method, European Journal of Remote Sensing 51(1): 231-240. https://doi.org/10.1080/22797254.2017.1419441.

Miller JD, Thode AE (2007) Quantifying burn severity in a heterogeneous landscape with a relative version of the delta Normalized Burn Ratio (dNBR), Remote Sensing of Environment 109: 66-80. https://doi.org/10.1016/j.rse.2006.12.006. 
Mitri GH, Gitas IZ (2006) Fire type mapping using object-based classification of Ikonos imagery. International Journal of Wildland Fire 15:457-462. https://doi.org/10.1071/WF05085.

Novelli A, Aguilar MA, Nemmaoui A, Auilar FJ, Tarantino E (2016) Performance evaluation of object based greenhouse detection fromSentinel-2 MSI and Landsat 8 OLI data: A case study from Almería(Spain), International Journal of Applied Earth Observation and Geoinformation 52: 403-411. https://doi.org/10.1016/j.jag.2016.07.011.

Özkan C (1998) Forest fire analysis with remote sensing data. MSc. Thesis, Istanbul Technical University, Graduate School of Science, Engineering and Technology, Geodesy and Photogrammetry Engineering Department, Istanbul, Turkey.

Parks SA, Dillon GK, Miller C (2014) A New Metric for Quantifying Burn Severity: The Relativized Burn Ratio. Remote Sensing 6: 1827-1844. https://doi.org/10.3390/rs6031827.

Pinty B, Verstraete MM (1992) GEMI: a non-linear index to monitor global vegetation from satellites. Vegetatio 101: 15-20.

Polychronaki A, Gitas IZ (2012) Burned Area Mapping in Greece Using SPOT-4 HRVIR Images and Object-Based Image Analysis. Remote Sensing 4: 424-438. https://doi.org/10.3390/rs4020424.

Quintano C, Fernández-Manso A, Fernández-Manso O (2018) Combination of Landsat and Sentinel-2 MSI data for initial assessing of burn severity, International Journal Applied Earth Observation Geoinformation 64:221-225. https://doi.org/10.1016/j.jag.2017.09.014.

Tucker C (1979) Red and photographic infrared linear combinations for monitoring vegetation. Remote Sensing of Environment 8: 127-150.

Türkeş M, Altan G (2012) Çanakkale'nin 2008 Yılı Büyük Orman Yangınlarının Meteorolojik ve Hidroklimatolojik Analizi. Coğrafi Bilimler Dergisi 10(2): 195-218. https://doi.org/10.1501/Cogbil_0000000137.

Vlassova L, Pérez-Cabello F, Mimbrero M, Llovería R, García-Martín A (2014) Analysis of the Relationship between Land Surface Temperature and Wildfire Severity in a Series of Landsat Images, Open Access Remote Sensing 6: 6136-6162. https://doi.org/10.3390/rs6076136.

Yurtseven H (2014) Using of high resolution satellite images in object based image analysis. $\mathrm{PhD}$ Thesis, Istanbul University, Graduate School of Science and Engineering Department of Forest Engineering, Istanbul, Turkey.

Xiao X, Braswell B, Zhang Q, Boles S, Frolking S, Moore III B (2003) Sensitivity Of Vegetation Indices to Atmospheric Aerosols: 66 Continental-Scale Observations in Northern Asia. Remote Sensing of Environment 84(3):385-392. https://doi.org/10.1016/S00344257(02)00129-3. 


\section{Figures}

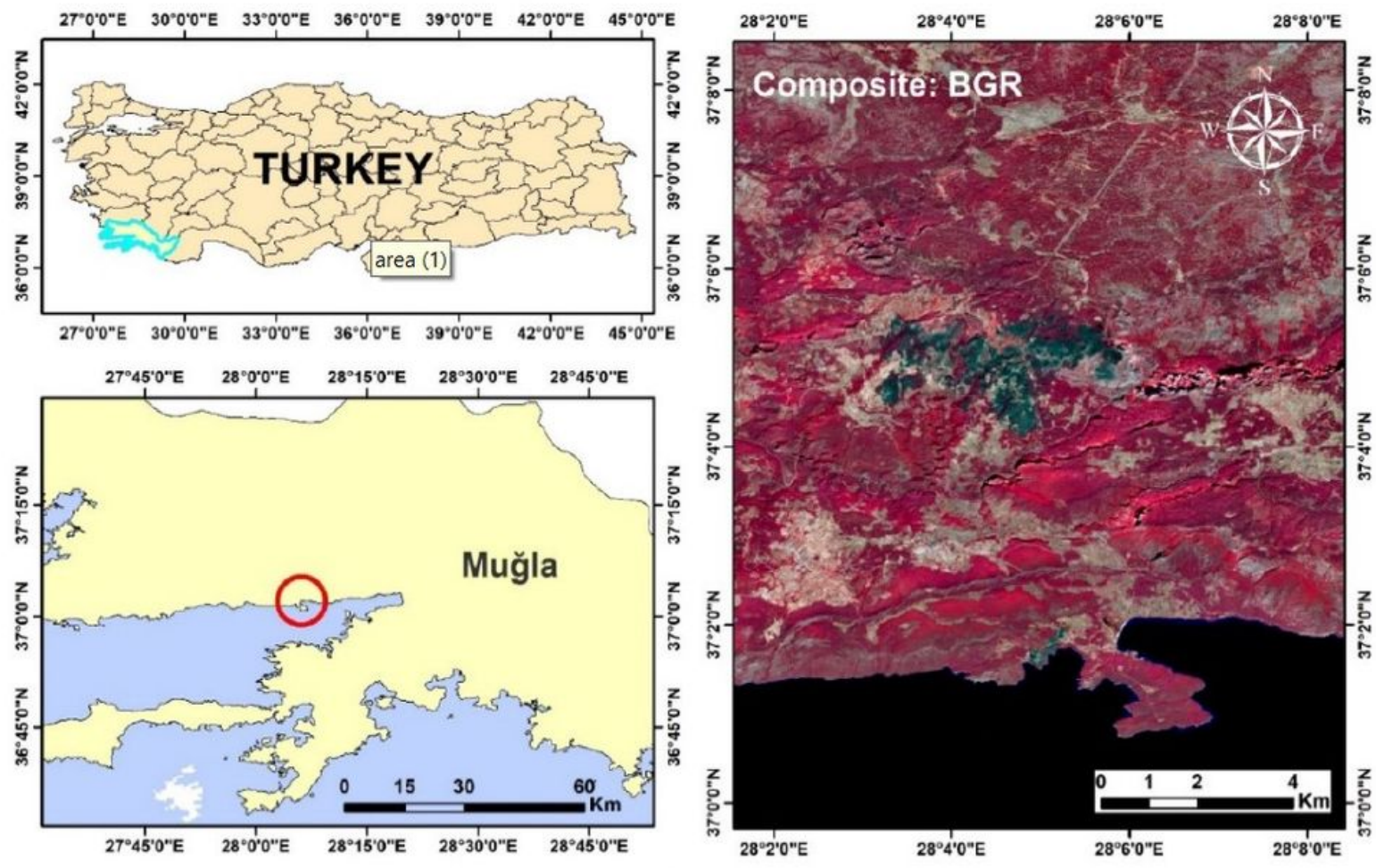

Fig. 1 Study area

\section{Figure 1}

study area

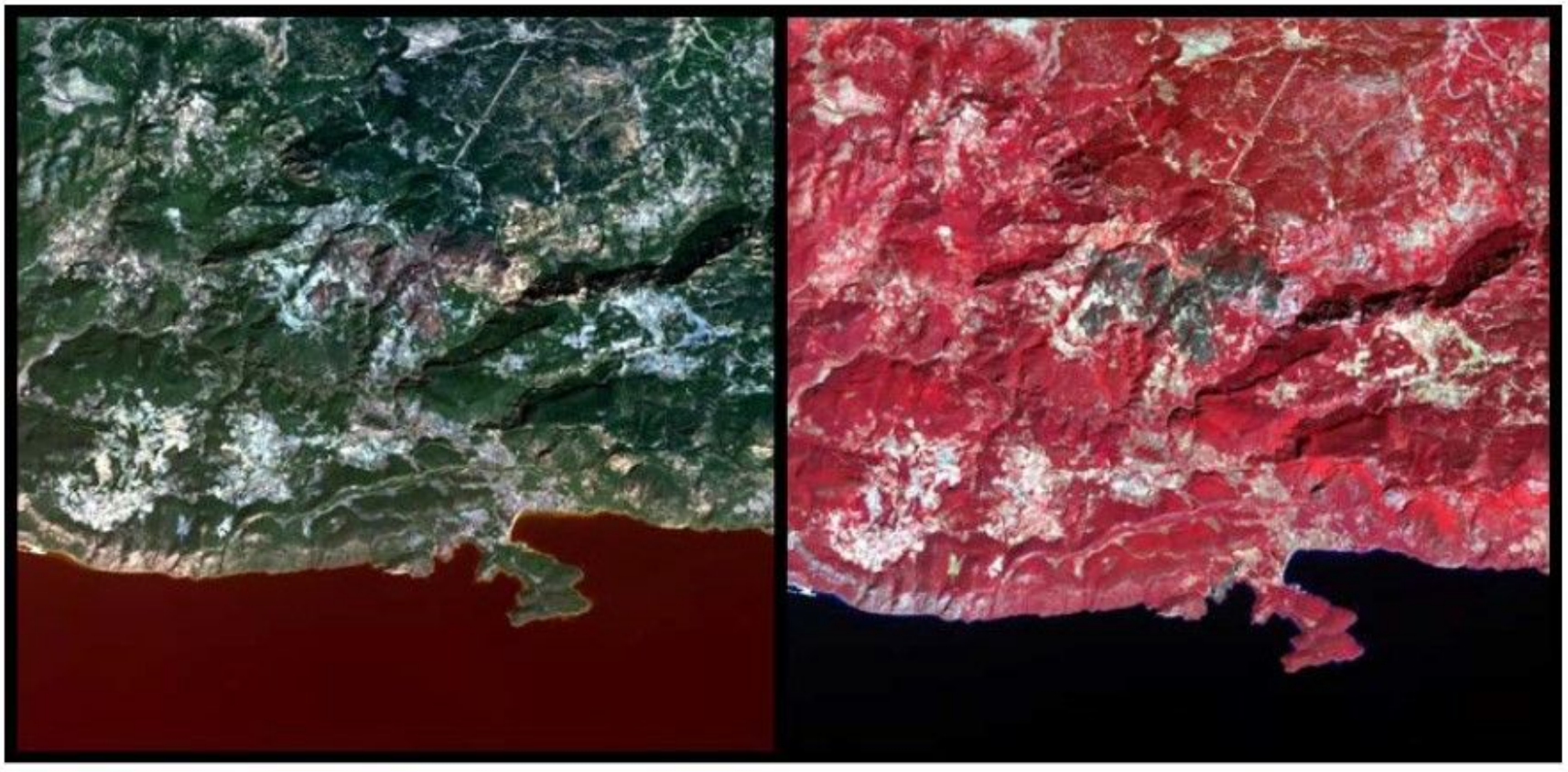

Fig. 2 Landsat-8 satellite of the study area after the fire a) true color (B4, B3, B2), b) false color (B5, B3, B2) 


\section{Figure 2}

Landsat-8 satellite of the study area after the fire a) true color (B4, B3, B2), b) false color (B5, B3, B2)

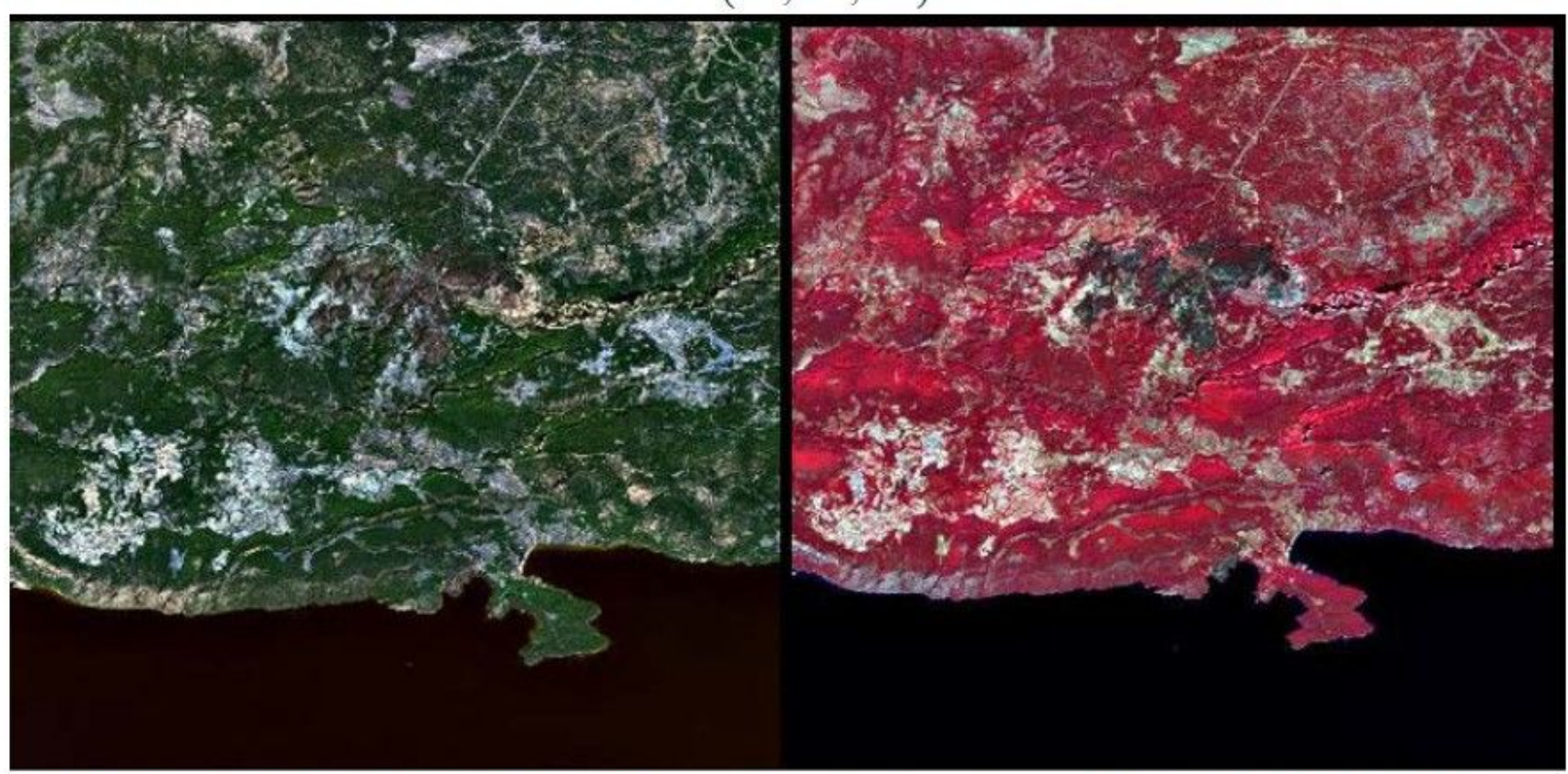

Fig 3. Sentinel-2 satellite of the study area after the fire a) true color (B4, B3, B2), b) false color (B8, B3, B2)

\section{Figure 3}

Sentinel-2 satellite of the study area after the fire a) true color (B4, B3, B2), b) false color (B8, B3, B2) 


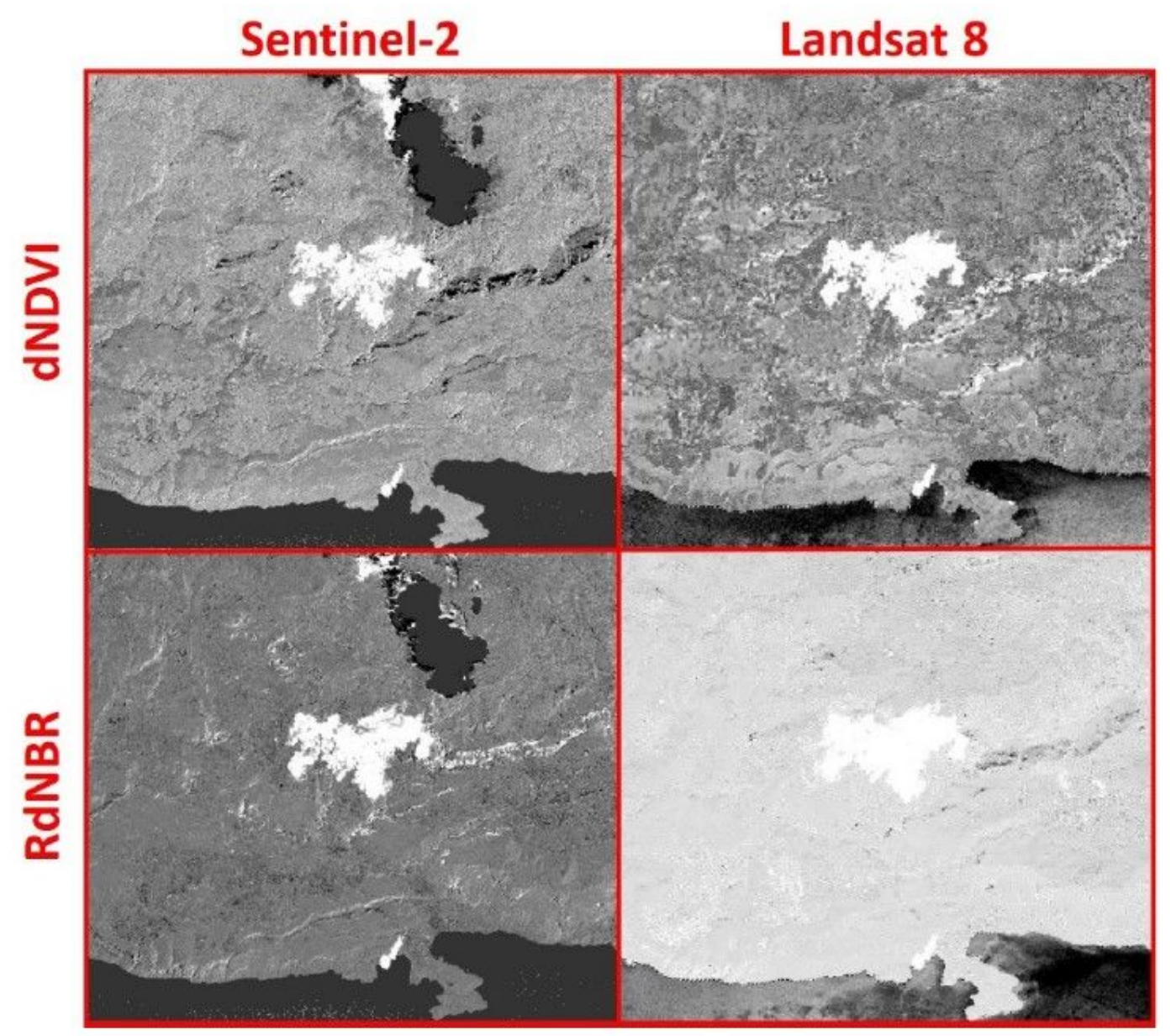

Fig. 4 dNDVI and RdNBR results of Sentinel-2 and Landsat-8

\section{Figure 4}

dNDVI and RdNBR results of Sentinel-2 and Landsat-8

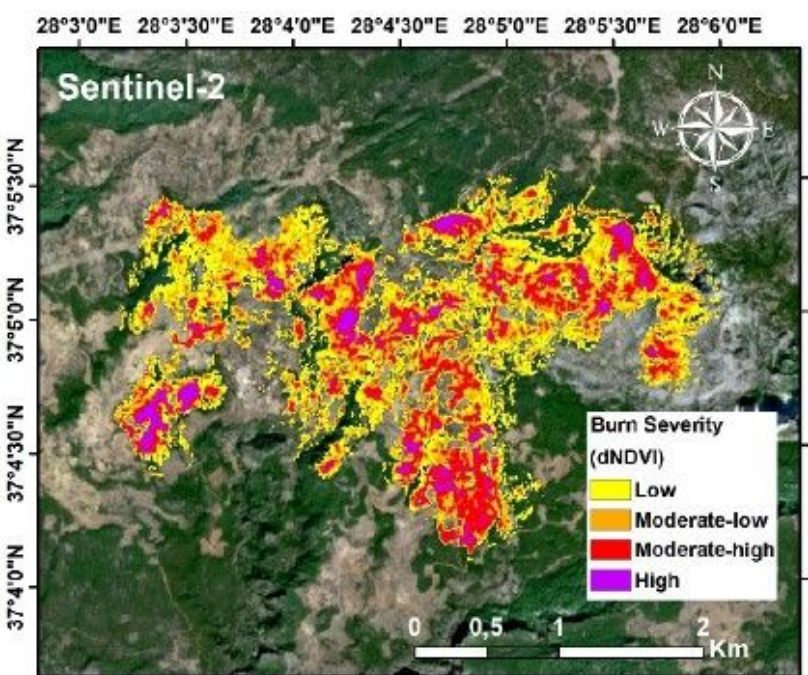

$28^{\circ} 3^{\prime} 0^{\prime \prime E} 28^{\circ} 3^{\prime} 30^{\prime \prime}$ E $28^{\circ} 4^{\prime} 0^{\prime \prime}$ E $28^{\circ} 4^{\prime} 30^{\prime \prime E} 28^{\circ} 5^{\prime} 0^{\prime \prime E} 28^{\circ} 5^{\prime} 30^{\prime \prime}$ E $28^{\circ} 6^{\prime} 0^{\prime \prime}$

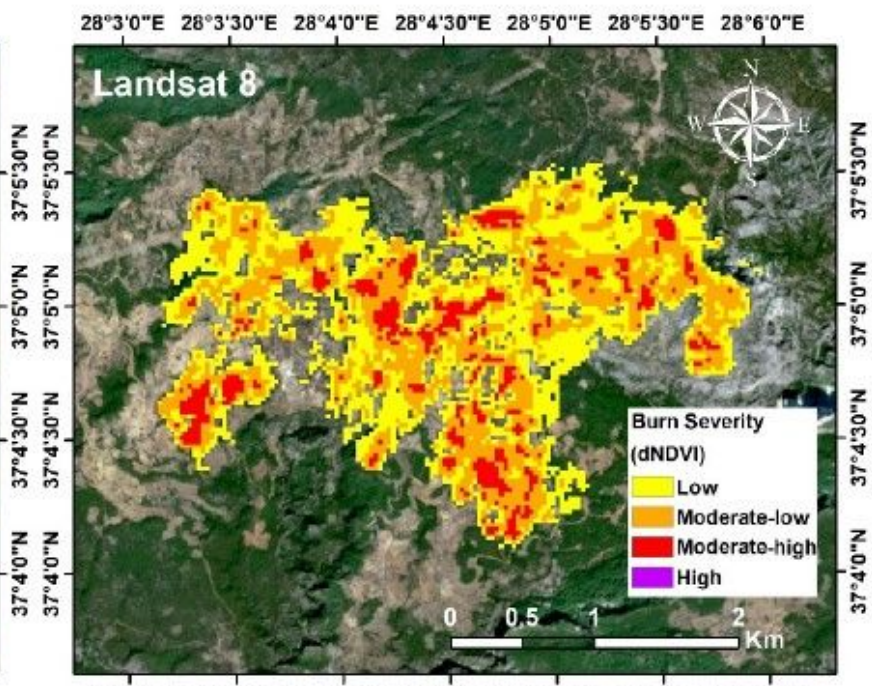

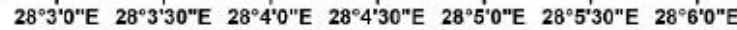

Fig. 5 Severity analysis using dNDVI of Sentinel-2 and Landsat-8 
Figure 5

Severity analysis using dNDVI of Sentinel-2 and Landsat-8 